\title{
NSAIDs for Prophylaxis for Heterotopic Ossification After Total Hip Arthroplasty: A Bayesian Network Meta-analysis
}

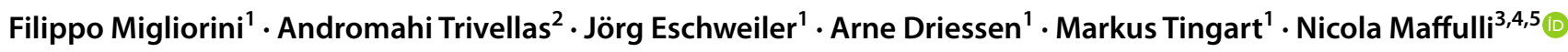

Received: 18 June 2020 / Accepted: 29 September 2020 / Published online: 12 October 2020

(c) The Author(s) 2020

\begin{abstract}
Non-steroidal anti-inflammatory drugs (NSAID) have been recommended to prevent of heterotopic ossification (HO) after total hip arthroplasty (THA), but debates are still ongoing. The present Bayesian network meta-analysis of randomized clinical trials (RCTs) compared all available pathways of NSAID treatment as prophylaxis for HO after THA. The present Bayesian network meta-analysis was conducted according to The PRISMA Extension Statement for Reporting of Systematic Reviews Incorporating Network Meta-analyses of Health Care Interventions guidelines. All randomized clinical trials comparing two or more interventions to prevent $\mathrm{HO}$ after THA were considered for analysis. HO was classified according to Brooker. The quality of the methodological assessment was performed through the risk of bias summary tool of the Review Manager Software 5.3 (The Cochrane Collaboration, Copenhagen). The network meta-analysis was performed through a STATA routine for Bayesian hierarchical random-effects model analysis, with log odd ratio (LOR) effect measure. Data from 26 studies (6396 THAs; 58\% females) were collected. The mean follow-up was 10.50 \pm 5.7 months. ANOVA showed good comparability among mean age and gender $(P>0.5)$. Celecoxib demonstrated the highest rate of Brooker class 0 (LOR 6.96), followed by diclofenac (LOR 6.94). Naproxen demonstrated the lowest rate of Brooker I HO (LOR 2.82), followed by celecoxib (LOR 3.52). Celecoxib demonstrated lowest rate of Brooker class II HO (LOR 1.66), class III (LOR), and class IV (LOR 0.25). The equation for global linearity detected no statistically significant inconsistency $(P>0.5)$ in all the comparisons. The present Bayesian network meta-analysis encourages the use of celecoxib as a prophylaxis for HO. These conclusions must be interpreted in light of the limitations of the present study. Future investigations are required to establish more definitely the role of celecoxib.
\end{abstract}

Level of Evidence: I, Bayesian network analysis of RCTs.

Keywords Heterotopic ossification · Total hip arthroplasty $\cdot$ NSAID

Nicola Maffulli

n.maffulli@qmul.ac.uk

1 Department of Orthopaedics, RWTH Aachen University Clinic, Pauwelstr. 31, 52074 Aachen, Germany

2 Department of Orthopaedics, David Geffen School of Medicine at UCLA, 10833 Le Conte Ave, Los Angeles, CA 90095, USA

3 Department of Medicine, Surgery and Dentistry, University of Salerno, Via S. Allende, 84081 Baronissi, SA, Italy

4 School of Pharmacy and Bioengineering, Keele University School of Medicine, Thornburrow Drive, Stoke on Trent, England

5 Barts and the London School of Medicine and Dentistry, Mile End Hospital, Centre for Sports and Exercise Medicine, Queen Mary University of London, 275 Bancroft Road, London E1 4DG, England

\section{Introduction}

Heterotopic ossification (HO) is common after total hip arthroplasty (THA) [1], and is characterized by the formation of ectopic bone within the surrounding muscle and soft tissues. If no prophylactic treatment is implemented, the incidence of $\mathrm{HO}$ ranges between 15 and 90\% [2-4]. In patients with high risk of HO, radiotherapy is recommended [5]. Alternatively, NSAID have been recommended to prevent $\mathrm{HO}$ after THA [6]. Several studies compared the use of NSAIDs against HO after THA [7-11], but the most effective prophylactic treatment remains elusive, and no evidence-based guidelines to prevent $\mathrm{HO}$ after THA are available. Several meta-analyses have been performed, but the drug of choice has not yet been identified, and debates are ongoing. The limit of these articles is intrinsic in the 
statistical nature of meta-analyses, which allows to compare only two treatments for the same intervention. Differently, in network meta-analyses multiple treatments $(\geq 3)$ can be compared using both direct comparisons of interventions within RCTs and indirect comparisons across trials [12]. Therefore, we performed a Bayesian network meta-analysis of RCTs comparing all the available NSAID treatments as prophylaxis for HO after THA to identify the most suitable drug(s) for prophylaxis. This study adds to the existent literature evidenced-based recommendations concerning the optimal pharmacological strategy to prevent HO after THA.

\section{Materials and Methods}

\section{Search Strategy}

The present Bayesian network meta-analysis was conducted according to the PRISMA Extension Statement for Reporting of Systematic Reviews Incorporating Network Metaanalyses of Health Care Interventions guidelines [13]. A primary protocol was established:

- P (patients): total hip arthroplasty;

- I (intervention): prevention of HO;

- C (comparison): oral therapy drugs;

- O (outcomes): grade of HO;

- S (study type): randomized clinical trial (RCT).

\section{Literature Search and Data Extraction}

Two independent authors (AD, FM) performed the literature search in September 2020. First, the following databases were accessed: Pubmed, Embase, Scopus, Google Scholar. The search covered from initiation of the database to September 2020. The following keywords were used in combination: total hip arthroplasty, replacement, prosthesis, heterotopic ossification, NSAID, COX-inhibitors, impingement, indomethacin, naproxen, acetylsalicylic acid, celecoxib, meloxicam, rofecoxib, ibuprofen, diclofenac. Two independent authors (AD, FM) performed data extraction. If the title and abstract matched the topic, the full-text was accessed. The bibliographies of the considered articles were also screened for inclusion. Disagreements were debated and solved by a third author (MT).

\section{Eligibility Criteria}

All randomized clinical trials comparing two or more interventions used to prevent $\mathrm{HO}$ formation were considered for analysis in the present study. According to the authors' language capabilities, articles in English, French, German, Italian, Portuguese and Spanish were considered.
Only level I of evidence RCTs according to the Oxford Centre of Evidenced-Based Medicine [14] were included. Editorials, cohort studies, review and meta-analyses, expert opinion and letters were excluded. Animals, biomechanics, cadaveric and in vitro studies were also excluded. Grades of $\mathrm{HO}$ were evaluated using the Brooker classification [15]. Other classification systems were not considered in the present study. Protocols for prevention of HO using ionizing radiations were not considered in the present study. Only articles reporting quantitative data concerning the outcomes of oral drug consumption to prevent $\mathrm{HO}$ were included in the present study. Missing data under the outcomes of interest warranted the exclusion from the present network meta-analysis.

\section{Data extraction and Outcomes of Interest}

Data extraction was performed by two independent authors (AD, FM). The following data were collected: generalities of the studies (author, year), duration of the follow-up (months), type of treatment and related protocol, number of samples, mean age and percentage of females among the study cohort. The outcome of interest was to evaluate the effect of oral non-steroidal anti-inflammatory drugs to prevent $\mathrm{HO}$ defined according to the modified Brooker Staging System (Table 1). This classification differs from the original by an additional grade 0 , in which there is no sign of $\mathrm{HO}[16]$.

\section{Methodological Quality Assessment}

The quality of the methodological assessment was performed through the risk of bias summary tool of the Review Manager Software 5.3 (The Cochrane Collaboration, Copenhagen). For the present analysis, six items from each study were evaluated: allocation, randomization, blinding of the assessors, selective reporting, incomplete data, and unknown source of bias.

Table 1 Modified Brooker Staging System

\begin{tabular}{ll}
\hline Class & Radiographic findings \\
\hline Grade 0 & $\begin{array}{l}\text { No sign of heterotopic ossification } \\
\text { Grade I }\end{array}$ \\
Brade II & $\begin{array}{l}\text { Exophe islands in the soft tissue around the hip } \\
\text { femur with at least } 1 \mathrm{~cm} \text { between opposing bone } \\
\text { surfaces } \\
\text { Exade III }\end{array}$ \\
& $\begin{array}{l}\text { Exophytes in the pelvis or proximal end of the } \\
\text { femur with less than } 1 \mathrm{~cm} \text { between opposing } \\
\text { bone surfaces }\end{array}$ \\
Grade IV & Bony ankylosis between proximal femur and pelvis
\end{tabular}




\section{Statistical Analysis}

The statistical analysis was performed by the first author (FM). For baseline comparability, the ANOVA test was performed using the IBM SPSS Software version 25, with a $P>0.5$ considered statistically significant. Analytical statistics was performed using the STATA Software/MP, Version 16 (Stata Corporation, College Station, Texas, USA). The same software was used to produce an additional graphic (Fig. 4) that displays the results, specifically of the rate of $\mathrm{HO}$ according to the modified Brooker classification for each drug. The network meta-analyses were performed through a Stata routine for Bayesian hierarchical random-effects model analysis. For the binary data, the effect estimates were evaluated through the natural logarithm of the odds ratio (LOR) statistical method [17]. Placebo was not considered as proper reference. Rather, the comparisons were matched to a reference group of "no event". Thereby, the final effect of each treatment ranks with respect to the reference group "no event". The overall inconsistency was obtained through the equation for global linearity via the Wald test. If the $P$ value $>0.5$, the null hypothesis cannot be rejected, and the consistency assumption could be accepted at the overall level of each treatment. Both confidence (CI) and percentile (PrI) intervals were set at 95\%. Edge plots were performed in all comparisons to evaluate the amount of direct and indirect observations. Interval plots were produced in all comparisons to rank the treatments according to the reference value and related effect size. Funnel plots were generated to estimate the risk of publication bias by plotting the natural logarithm of an individual study effect size against the standard error of the natural logarithm of an individual study effect size. This methodology has been already used in previous studies [18-21]. A further meta-analysis comparing subgroups selective vs non-selective NSAID was performed. The STATA Software/MP was used. For the comparison, the Mantel-Haenszel statistic method for dichotomous data was adopted, with odds ratio (OR) effect measure. The CI was set at $95 \%$. The Higgins- $I^{2}$ test was performed to evaluate heterogeneity. If the Higgins $-I^{2}$ test was $>50 \%$, high heterogeneity was detected, the data were analysed through a random model effect. If the Higgins- $I^{2}$ test was $<50 \%$, a fixed effect model was adopted. $P$ values $<0.05$ were considered statistically significant.

\section{Results}

\section{Search Result}

The literature search resulted in 302 articles, of which 97 were RCTs. After removal of duplicates $(N=27)$, a further 32 articles were excluded either because they did not report quantitative data $(N=9)$, language limitation $(N=3)$, animal or biomechanical or cadaveric studies $(N=12)$, focused only on radiation $(N=18)$, or delivered uncertain data $(N=2)$. Ultimately, 26 RCTs were included in the present study. The flow chart of the literature search is shown in Fig. 1.

\section{Methodological Quality Assessment}

In concert with the above-mentioned assessment of risk of bias, a low risk of selection bias can be evidenced. Similarly, attrition and reporting bias can be considered a moderate to low risk. The risk of unknown bias is also moderate to low. Therefore, the methodological assessment of this work can be judged as a very good quality. The Cochrane risk of bias summary tool is shown in Fig. 2.

\section{Risk of Publication Bias}

The analysis of the funnel plots detected good symmetrical distribution of the referral points. All referral points among the funnel plots were under the range of acceptability. The risk of publication bias was low. The funnel plots are reported in Fig. 3.

\section{Patient Demographics}

Data from 6396 (58\% females) THAs were collected. The mean follow-up was $10.50 \pm 5.7$ months. The mean

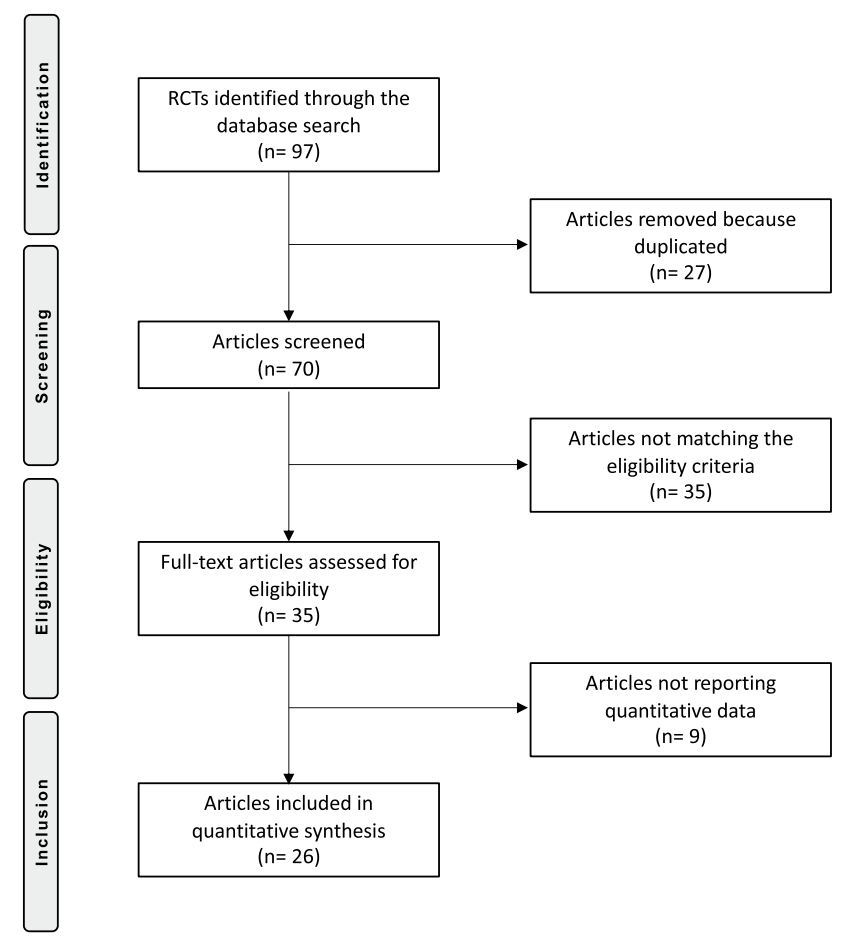

Fig. 1 PRISMA Literature search flow chat 


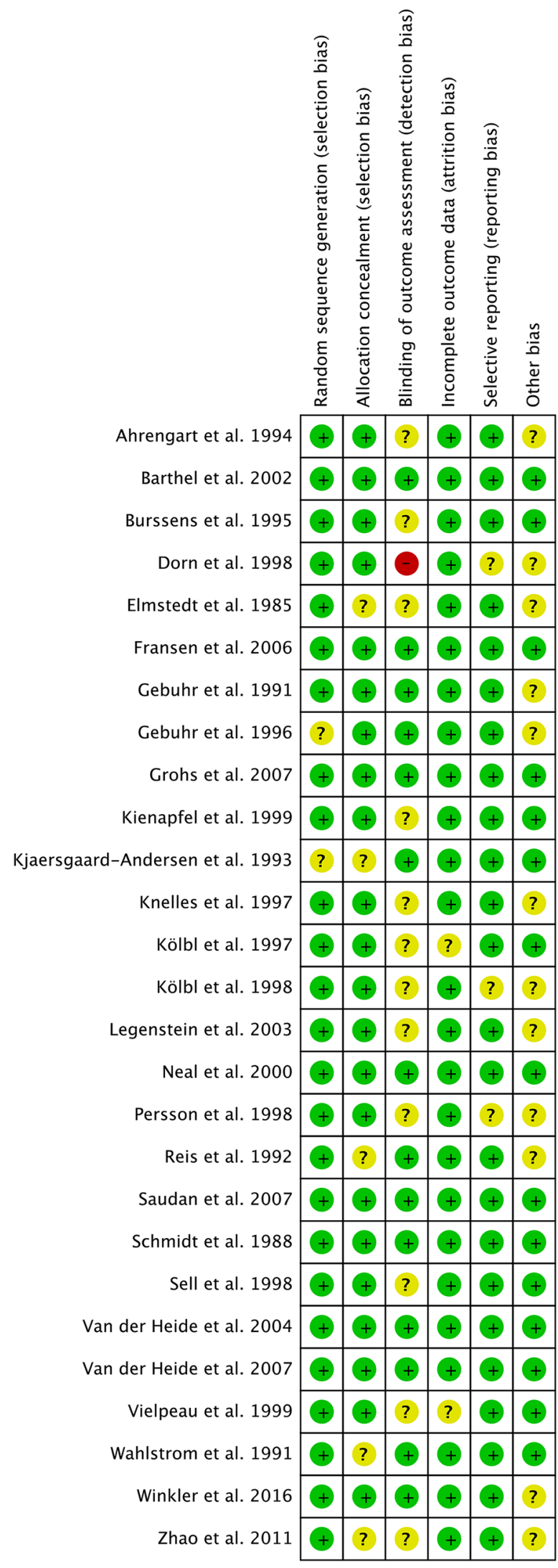

Fig. 2 Cochrane risk of bias summary tool age of the patients was $66.30 \pm 3.6$ years. The mean duration of the drug administration for $\mathrm{HO}$ prevention was $20.95 \pm 18.3$ days. ANOVA showed good comparability in mean age and gender $(P>0.5)$. Table 2 shows the demographic baseline of the studies, while Table 3 shows the daily dose and treatment duration of each drug.

\section{Outcomes of Interest}

Celecoxib demonstrated the highest rate of modified Brooker class 0 (LOR 6.96; 95\% CI 5.69 to 8.23), followed by diclofenac (LOR 6.94; 95\% CI 5.73 to 8.16). Naproxen demonstrated the lowest rate of $\mathrm{HO}$ according to the Brooker class II (LOR 2.82; 95\% CI 1.50 to 4.14), followed by celecoxib (LOR 3.52; 95\% CI 2.33 to 4.71). Celecoxib demonstrated the lowest rate of $\mathrm{HO}$ according to the Brooker class II (LOR 1.66; 95\% CI 0.21 to 3.12), followed by acetylsalicylic acid (LOR 2.18; 95\% CI 0.92 to 3.43). Celecoxib demonstrated the lowest rate of $\mathrm{HO}$ according to the Brooker class III (LOR 0.56 ; $95 \%$ CI -1.71 to 2.83 ), followed by naproxen (LOR 0.67; 95\% CI -2.93 to 4.26). Celecoxib demonstrated the lowest rate of $\mathrm{HO}$ according to the Brooker class IV (LOR 0.25 ; $95 \% \mathrm{CI}-3.22$ to 3.73 ), followed by indomethacin (LOR $0.49 ; 95 \% \mathrm{CI}-0.53$ to 1.51 ). The equation for global linearity detected no statistically significant inconsistency $(P>0.5)$ in all the comparisons. These results are shown in greater detail in Fig. 3, while Fig. 4 displays the rate of the $\mathrm{HO}$ according to the modified Brooker classification for each drug.

\section{Subgroup Analysis: Non-selective NSAIDs Versus Selective NSAIDs}

Selective NSAIDs compared to the non-selective NSAIDs resulted not significant in all the comparisons: Brooker class 0 (OR $1.68 ; 95 \%$ CI 0.97 to $2.90 ; P=0.6$ ), class I (OR $0.74 ; 95 \%$ CI 0.46 to $1.20 ; P=0.2)$, class II $(0.82 ; 95 \% \mathrm{CI}$ 0.60 to $1.10 ; P=0.2$ ), class III (OR $1.07 ; 95 \%$ CI 0.66 to $1.73 ; P=0.8$ ), and class IV (OR 2.06; $95 \%$ CI 0.46 to 9.16 ; $P=0.3)$.

\section{Discussion}

The present Bayesian network meta-analysis demonstrated that prophylaxis with celecoxib was associated with the lowest rate of $\mathrm{HO}$ after THA, followed by diclofenac and naproxen. On the other hand, tenoxicam, acetylsalicylic acid, and meloxicam were associated with the highest rate of HO following THA. Subgroup analysis of COX-2 selective versus non-selective NSAID demonstrated no statistically consistent difference. 

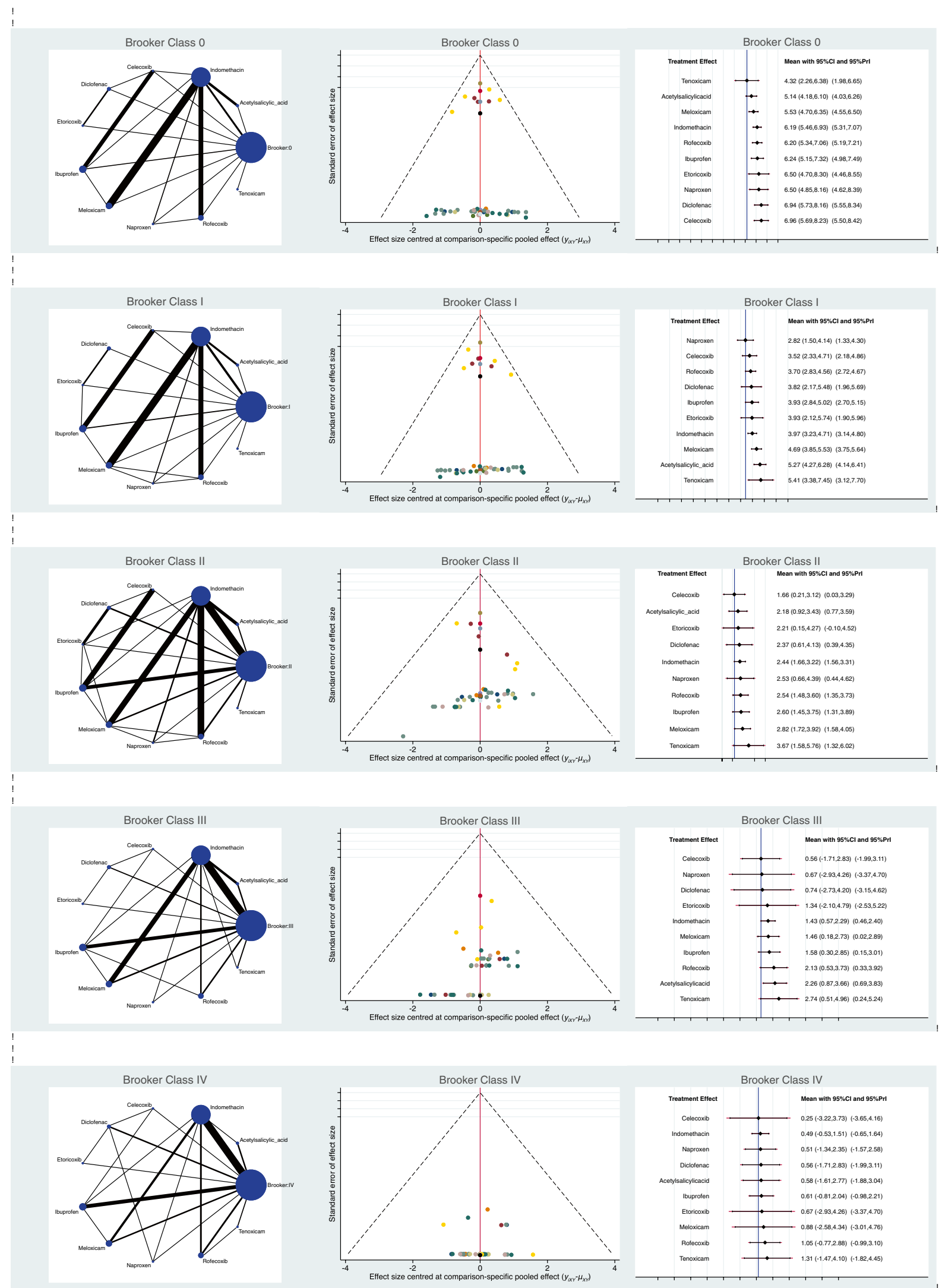

Fig. 3 Overall results: edge, interval, and funnel plots of the network comparisons. Celecoxib, diclofenac and naproxen are the drugs with the higher rate of "no sign of HO" (modified Brooker class 0), and also those with the lowest rate of HO signs in the Brooker classes I, II, III, IV 
Table 2 Demographic baseline of the studies (NR: not reported)

\begin{tabular}{|c|c|c|c|c|c|c|}
\hline Author, year & $\begin{array}{l}\text { Follow-up } \\
\text { (months) }\end{array}$ & Type of treatment & Type of protocol & Samples $(n)$ & Mean age & $\begin{array}{l}\text { Female } \\
\text { gender } \\
(\%)\end{array}$ \\
\hline \multirow[t]{2}{*}{ Ahrengart et al. 1994 [22] } & \multirow[t]{2}{*}{12} & Ibuprofen & $1500 \mathrm{mg}$ daily/9 days & 21 & 70.0 & 52.6 \\
\hline & & Placebo & Placebo & 26 & 70.0 & 52.6 \\
\hline \multirow[t]{3}{*}{ Barthel et al. 2002 [23] } & \multirow[t]{3}{*}{12} & Meloxicam & $7.5 \mathrm{mg}$ daily/14 days & 24 & 65.0 & 42.3 \\
\hline & & Meloxicam & $15 \mathrm{mg}$ daily/14 days & 115 & 63.0 & 65.0 \\
\hline & & Indomethacin & $100 \mathrm{mg}$ daily/14 days & 111 & 63.0 & 64.2 \\
\hline \multirow[t]{3}{*}{ Burssens et al. 1995 [24] } & \multirow[t]{3}{*}{6} & Tenoxicam & $10 \mathrm{mg}$ daily/42 days & 27 & 61.0 & \\
\hline & & Tenoxicam & $20 \mathrm{mg}$ daily/42 days & 26 & 59.0 & \\
\hline & & Placebo & Placebo & 27 & 62.0 & \\
\hline \multirow[t]{2}{*}{ Dorn et al. 1998 [25] } & \multirow[t]{2}{*}{12} & Indomethacin & $150 \mathrm{mg}$ daily/4 days & 104 & & 61.5 \\
\hline & & Indomethacin & $150 \mathrm{mg}$ daily/8 days & 105 & & 60.0 \\
\hline \multirow[t]{2}{*}{ Elmstedt et al. 1985 [26] } & \multirow[t]{2}{*}{12} & Ibuprofen & $1200 \mathrm{mg}$ daily/92 days & 21 & 70.0 & 52.4 \\
\hline & & Placebo & Placebo & 21 & 70.0 & 60.0 \\
\hline \multirow[t]{2}{*}{ Fransen et al. 2006 [27] } & \multirow[t]{2}{*}{12} & Ibuprofen & $1200 \mathrm{mg}$ daily/14 days & 391 & 66.0 & 45.0 \\
\hline & & Placebo & Placebo & 407 & 67.0 & 45.6 \\
\hline \multirow[t]{2}{*}{ Gebuhr et al. 1991 [28] } & \multirow[t]{2}{*}{12} & Naproxen & $750 \mathrm{mg}$ daily/28 days & 28 & 75.0 & 60.7 \\
\hline & & Placebo & Placebo & 27 & 70.0 & 55.5 \\
\hline \multirow[t]{2}{*}{ Gebuhr et al. 1996 [29] } & \multirow[t]{2}{*}{12} & Tenoxicam & $40 / 20 \mathrm{mg}$ daily/5 days & 61 & 72.0 & \\
\hline & & Placebo & Placebo & 62 & 72.0 & \\
\hline \multirow[t]{2}{*}{ Grohs et al. 2007 [30] } & \multirow[t]{2}{*}{12.0} & Rofecoxib & $25 \mathrm{mg}$ daily/7 days & 50 & 60.0 & 66.0 \\
\hline & & Indomethacin & $100 \mathrm{mg}$ per daily/7 days & 50 & 60.0 & 60.0 \\
\hline \multirow[t]{2}{*}{ Kienapfel et al. 1999 [31] } & \multirow[t]{2}{*}{18} & Indomethacin & $100 \mathrm{mg}$ daily/42 days & 55 & 64.4 & 60.0 \\
\hline & & Control group & No treatment & 50 & 66.0 & 76.0 \\
\hline \multirow[t]{2}{*}{ Kjaersgaard-Andersen et al. 1993 [32] } & 3 & Indomethacin & $100 \mathrm{mg}$ daily/14 days & 34 & 72 & 68.4 \\
\hline & & Placebo & Placebo & 34 & 70 & 63.6 \\
\hline Knelles et al. 1997 [33] & 12 & Indomethacin & $100 \mathrm{mg}$ daily/14 days & 90 & 67.0 & 68.0 \\
\hline & & Indomethacin & $100 \mathrm{mg}$ daily/7 days & 113 & 64.7 & 72.0 \\
\hline & & Acetylsalicylic acid & $2250 \mathrm{mg}$ daily/14 days & 93 & 66.5 & \\
\hline & & Control group & No treatment & 100 & 65.3 & 69.0 \\
\hline Kölbl et al. 1997 [34] & 12 & Indomethacin & $100 \mathrm{mg}$ daily/7 days & 113 & 64.7 & 63.7 \\
\hline & & Control group & No treatment & 100 & 65.3 & 69.0 \\
\hline Kölbl et al. 1998 [35] & 6 & Diclofenac & $150 \mathrm{mg}$ daily/14 days & 54 & 63.9 & 51.8 \\
\hline & & Control group & No treatment & 100 & 65.3 & 69.0 \\
\hline Legenstein et al. 2003 [36] & 6 & Indomethacin & $150 \mathrm{mg}$ daily/12 days & 58 & 68.0 & 59.0 \\
\hline & & Meloxicam & $7.5 \mathrm{mg}$ daily/12 days & 58 & 65.0 & 74.0 \\
\hline Neal et al. 2000 [37] & 9 & Acetylsalicylic acid & $162 \mathrm{mg}$ daily/35 days & 1039 & 66.0 & 50.0 \\
\hline & & Placebo & Placebo & 1009 & 65.0 & 51.0 \\
\hline Persson et al. 1998 [38] & 12 & Ibuprofen & $1200 \mathrm{mg}$ daily/21 days & 48 & & 50.0 \\
\hline & & Ibuprofen & $1200 \mathrm{mg}$ daily/7 days & 48 & & 50.0 \\
\hline & & Placebo & Placebo & 47 & & 53.3 \\
\hline Reis et al. 1992 [39] & 24 & Diclofenac & $150 \mathrm{mg}$ daily/42 days & 80 & & \\
\hline & & Placebo & Placebo & 80 & & \\
\hline Saudan et al. 2007 [40] & 3 & Celecoxib & $400 \mathrm{mg}$ daily/10 days & 117 & 69.0 & 53.0 \\
\hline & & Ibuprofen & $1200 \mathrm{mg}$ daily/10 days & 123 & 70.0 & 54.0 \\
\hline Schmidt et al. 1988 [41] & & Indomethacin & $75 \mathrm{mg}$ daily/42 days & 102 & 67.0 & \\
\hline & & Placebo & Placebo & 99 & 68.0 & \\
\hline Van der Heide et al. 2004 [42] & 6 & Indomethacin & $150 \mathrm{mg}$ daily/7 days & 89 & 67.0 & 68.5 \\
\hline & & Meloxicam & 15 mg daily/7 days & 92 & 67.0 & 68.5 \\
\hline & & Control group & No treatment & 170 & & \\
\hline
\end{tabular}


Table 2 (continued)

\begin{tabular}{|c|c|c|c|c|c|c|}
\hline Author, year & $\begin{array}{l}\text { Follow-up } \\
\text { (months) }\end{array}$ & Type of treatment & Type of protocol & Samples $(n)$ & Mean age & $\begin{array}{l}\text { Female } \\
\text { gender } \\
(\%)\end{array}$ \\
\hline \multirow[t]{2}{*}{ Van der Heide et al. 2007 [43] } & 12 & Indomethacin & $150 \mathrm{mg}$ daily/7 days & 89 & & 62.4 \\
\hline & & Rofecoxib & $50 \mathrm{mg}$ daily/7 days & 85 & & 62.4 \\
\hline \multirow[t]{3}{*}{ Vielpeau et al. 1999 [44] } & 6 & Naproxen & $750 \mathrm{mg}$ daily/42 days & 28 & 66.0 & \\
\hline & & Indomethacin & $75 \mathrm{mg}$ daily/42 days & 28 & 63.9 & \\
\hline & & Placebo & Placebo & 28 & 62.8 & \\
\hline \multirow[t]{2}{*}{ Wahlstrom et al. 1991 [45] } & 24 & Diclofenac & $150 \mathrm{mg}$ daily/42 days & 50 & 71.0 & 40.0 \\
\hline & & Placebo & Placebo & 50 & 70.0 & 39.1 \\
\hline \multirow[t]{2}{*}{ Winkler et al. 2016 [46] } & 6 & Diclofenac & $150 \mathrm{mg}$ daily/9 days & 44 & 61.9 & 45.8 \\
\hline & & Etoricoxib & $90 \mathrm{mg}$ daily/9 days & 45 & 60.2 & 46.8 \\
\hline \multirow[t]{2}{*}{ Zhao et al. 2011 [47] } & 1.5 & Celecoxib & 200 mg daily/42 days & 25 & 65.4 & \\
\hline & & Indomethacin & $75 \mathrm{mg}$ daily/42 days & 25 & 65.4 & \\
\hline
\end{tabular}

Table 3 Dose and duration of the therapy

\begin{tabular}{lll}
\hline Drug & $\begin{array}{l}\text { Daily administration } \\
(\mathrm{mg})\end{array}$ & $\begin{array}{l}\text { Mean duration of } \\
\text { assumption (days) }\end{array}$ \\
\hline Acetylsalicylic acid & 162 & 35.0 \\
Acetylsalicylic acid & 2250 & 14.0 \\
Celecoxib & 200 & 42.0 \\
Celecoxib & 400 & 10.0 \\
Diclofenac & 150 & 26.75 \\
Etoricoxib & 90 & 9.0 \\
Ibuprofen & 1500 & 9.0 \\
Ibuprofen & 1200 & 28.8 \\
Indomethacin & 75 & 42.0 \\
Indomethacin & 100 & 15.0 \\
Indomethacin & 150 & 7.6 .0 \\
Meloxicam & 7.5 & 13.0 \\
Meloxicam & 15 & 10.5 \\
Naproxen & 750 & 35.0 \\
Rofecoxib & 25 & 7.0 \\
Rofecoxib & 50 & 7.0 \\
Tenoxicam & 10 & 42.0 \\
Tenoxicam & 20 & 42.0 \\
Tenoxicam & 30 & 5.0 \\
\hline & &
\end{tabular}

A recent network meta-analysis included also radiation, which resulted to be the most effective method to prevent $\mathrm{HO}$ [48]. However, radiation is recommended only for patients at high risk: bilateral hypertrophic osteoarthritis, prior history of $\mathrm{HO}$, and arthritis caused by trauma characterized by hypertrophic osteophytosis [5, 49]. Potential adverse effects of radiation involve wound healing delays, fatigue and joint swelling. Trochanter non-union has been observed in $12 \%$ to $30 \%$ of patients after radiation [50]. Radiation may prevent acetabulum or proximal femur bone ingrowth, leading to failure in cementless and porous implants [5]. In male patients, even with low doses and testicular shielding, there is concern that radiation can reduces sperm count and activity [5]. Even if rare, secondary malignancies developed after hip irradiation [51, 52]. Regardless of the prophylaxis for $\mathrm{HO}$, for selected patients following THA post-operative NSAID pain therapy is often administered. Thus, prevention of HO via NSAID offers a comfortable and safe alternative.

In the present network meta-analysis, celecoxib showed powerful capability to reduce HO. Neal et al. [40], analysing celecoxib in a randomized study of 240 patients, found that a post-operative ten-day prophylaxis regimen reduced the risk of Brooker grade I HO by $50 \%$, and grades II and III by $75 \%$ compared to ibuprofen. In 2014, Lavernia et al. [53] analysed over 154 patients retrospectively, and found statistically significant lower rates of HO in the celecoxib cohort compared to the control group.

Similar results were found in a case-control study by Oni et al. [54]. In the present study, diclofenac yielded powerful capability to prevent HO. Two RCTs [35, 55], including in total 354 patients showed that diclofenac was as effective at preventing $\mathrm{HO}$ compared to radiation. In 2016, Winkler et al. [46] performed a prospective, double-blinded RCT comparing diclofenac versus etoricoxib: the two drugs were equally effective. Most other studies analysed indomethacin and ibuprofen. Among the various studies included, no consensus was demonstrated. Thus, it was no possible to analyse related protocols separately. This may increase the risk of bias and heterogeneity. Indeed, even in our study the heterogeneity was high, resulting in a wide CI of the outcomes.

Both ibuprofen and indomethacin are moderately capable to prevent HO. Two double-blinded RCTs [22, 27], collecting in total data from 949 patients, found no effect of ibuprofen on HO. Conversely, a double-blind RCT [42] detected reduced $\mathrm{HO}$ in patients treated with ibuprofen, but 


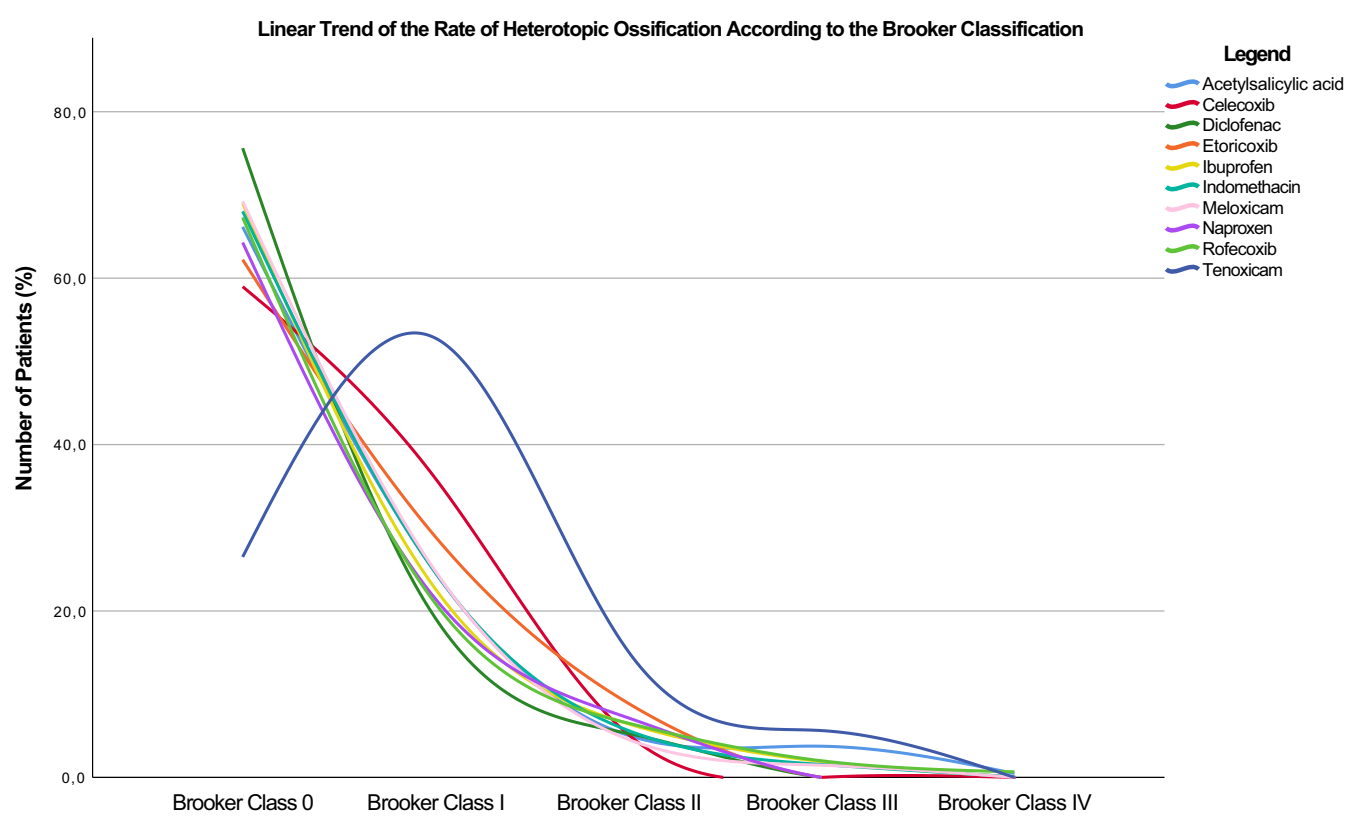

Fig. 4 Rate of HO according to the modified Brooker classification for each drug. Celecoxib followed by naproxen and diclofenac are those that have the greatest tendency to reduce according to the progression of the Brooker classes

no dose- or time-correlation was found. An RCT comparing 240 patients receiving celecoxib versus ibuprofen evidenced a reduced rate of $\mathrm{HO}$ development in the celecoxib cohort [40]. Another RCT (209 patients) [25] reported less severe $\mathrm{HO}$ in the indomethacin cohort compared to the control group. Van der Heide et al. [42, 43] reported comparable results with indomethacin versus rofecoxib and versus meloxicam.

In the present study, the use of naproxen as prophylaxis for HO was controversial. Although optimal in terms of Brooker 0 and I classes, naproxen is also correlated with a high increase of Brooker class III and IV HO, showing heterogeneous values and wide CI. Therefore, these data are not reliable and must be interpreted with caution. Vielpeau et al. [44] observed the efficacy of naproxen in a cohort of 84 patients, and found that naproxen is an effective and safe prophylaxis for $\mathrm{HO}$, and results were comparable to those observed with indomethacin. Further studies are required to investigate the role of naproxen as prophylaxis for HO.

In the present network meta-analysis, the effect of rofecoxib was moderate. Comparing Brooker class I HO, rofecoxib was comparable to celecoxib and diclofenac. However, data on this drug have been reported with high variability. Two RCTs enrolling 286 patients analysing the effect of rofecoxib found no differences when it was compared to indomethacin [30,43]. Similarly, fair results were reported with etoricoxib. Etoricoxib evidenced medium capability in the comparison of Brooker class 0 and I, but good capability in the comparison of Brooker class II and III. Concerning Brooker class IV HO, etoricoxib produced heterogeneous results and scored moderately. However, given the heterogeneous results of etoricoxib and rofecoxib, data from these comparisons should be interpreted with caution.

The present network meta-analysis showed that acetylsalicylic acid produced heterogeneous results, and provided moderate to fair capability of it to inhibit HO compared to other NSAIDs. Two RCTs including 2733 patients tested the efficacy of acetylsalicylic acid [33, 37]. The study interventions were different, but both investigations agreed that it had no major effect on heterotopic bone formation, and the balance of risks and benefits does not justify the use of acetylsalicylic acid for this purpose. Assessing meloxicam and tenoxicam, a fair efficacy to prevent $\mathrm{HO}$ was detected. Tenoxicam efficaciously prevented $\mathrm{HO}$ in two different drug administration protocols in a double-blind placebo RCT [24]. However, in our network comparisons, tenoxicam was not superior to the other drugs. Several authors evaluated the efficacy of meloxicam. A RCT comparing meloxicam versus indomethacin in a cohort of 272 patients found a statistically significant higher rate of $\mathrm{HO}$ in the meloxicam cohort [23]. Legenstein et al. [36] found no significant difference between meloxicam versus indomethacin in 116 patients. Similar results were found by Van der Heide et al. [42] in 182 patients. Accordingly, the evidence in favour of the use of tenoxicam and meloxicam for $\mathrm{HO}$ prevention is dubious.

Results from the subgroup analysis are in agreement with recent meta-analyses. In 2018, Zhu et al. [56] performed a meta-analysis comparing COX-2 selective NSAIDs versus non-selective NSAIDs. Analysing data from 1636 patients (8 RCTs), no differences were found between the two classes of 
medications. Similar results were found by Joice et al. [57] in 2018 analysing data from 29 studies (6695 patients). Similarly, Kan et al. [1] did not find differences among the two groups of drugs in 5995 patients. Furthermore, Grohs et al. [30] analysed the Harris hip score among patients treated with non-selective and selective COX-2 inhibitor NSAIDs for HO, evidencing no statistically significant differences. Given these comparable results, and the use of selective NSAIDs being associated with less side effects and post-operative bleeding compared to nonselective NSAIDs, their use should be encouraged [56-58]. To avoid untoward events, selective NSAIDs must be administered with caution in patients with cardiovascular risk.

The present network meta-analysis was precise and detailed, but this study has limitations. Firstly, the drug administration protocols analysed were different from one study included to the other. The high variability in treatment protocols produced high heterogeneity in the included articles. Therefore, conclusion from the present work must be interpreted with caution. Another important limitation is the relatively small number of RCTs eligible for inclusion, reflecting the lack of evidence in the published literature on this topic. Further high-quality studies are required to definitively establish the role of non-selective NSAIDs and administration protocols. Because of the lack of quantitative data, several drugs (e.g. calcitonin, flurbiprofen, ketorolac, ketoprofen) were not considered in the present study, representing another limitation. All the included articles, even those with follow-up shorter than 12 months, referred to the Brooker classification. We also must underline that, although HO formation generally is detectable early after surgery, its extent and Brooker grade can not be definitively assessed until 12 months after surgery. All the drugs were compared regardless to their daily intake or therapy duration. This represents an important limitation of the present study. As shown in Table 3, the daily intake and therapy duration were highly variable, increasing the risk of selection bias. This reflected the limited available data in the literature. We must further acknowledge that many studies are older than 20 years, and only two have been published in the last decade (2010-2019). In the light of these limitations, given the aforementioned controversies and the lack of consensus, the results of the present Bayesian network meta-analysis must be interpreted with caution. Future studies should progress from our results and conduct high-quality trials investigating, for example, the potential costs and benefits of Celecoxib as prophylaxis for $\mathrm{HO}$.

\section{Conclusion}

In total hip arthroplasty, the use of celecoxib as prophylaxis was associated with the lowest rate of HO. Tenoxicam, acetylsalicylic acid, and meloxicam were associated with the highest rates of HO. Subgroup analysis of COX-2 non-selective versus selective COX-2 inhibitors NSAIDs showed no statistically consistent difference. These conclusions must be interpreted within the limitations of the present study. Further investigations are required to improve current evidences.

Funding Open access funding provided by Università degli Studi di Salerno within the CRUI-CARE Agreement. No external source of funding was used.

\section{Compliance with Ethical Standards}

Conflict of interest Filippo Migliorini, Andromahi Trivellas, Jörg Eschweiler, Arne Driessen, Markus Tingart, and Nicola Maffulli declare that they have no conflicts of interest.

Ethical Approval This article does not contain any studies with human participants or animals performed by any of the authors.

Informed Consent For this type of study informed consent is not required.

Open Access This article is licensed under a Creative Commons Attribution 4.0 International License, which permits use, sharing, adaptation, distribution and reproduction in any medium or format, as long as you give appropriate credit to the original author(s) and the source, provide a link to the Creative Commons licence, and indicate if changes were made. The images or other third party material in this article are included in the article's Creative Commons licence, unless indicated otherwise in a credit line to the material. If material is not included in the article's Creative Commons licence and your intended use is not permitted by statutory regulation or exceeds the permitted use, you will need to obtain permission directly from the copyright holder. To view a copy of this licence, visit http://creativecommons.org/licenses/by/4.0/.

\section{References}

1. Kan SL, Yang B, Ning GZ, Chen LX, Li YL, Gao SJ, Chen XY, Sun JC, Feng SQ (2015) Nonsteroidal anti-inflammatory drugs as prophylaxis for heterotopic ossification after total hip arthroplasty: a systematic review and meta-analysis. Medicine (Baltimore) 94(18):e828. https://doi.org/10.1097/MD.0000000000000828

2. Zhu Y, Zhang F, Chen W, Zhang Q, Liu S, Zhang Y (2015) Incidence and risk factors for heterotopic ossification after total hip arthroplasty: a meta-analysis. Arch Orthop Trauma Surg 135(9):1307-1314. https://doi.org/10.1007/s00402-015-2277-8

3. Macfarlane RJ, Ng BH, Gamie Z, El Masry MA, Velonis S, Schizas C, Tsiridis E (2008) Pharmacological treatment of heterotopic ossification following hip and acetabular surgery. Expert Opin Pharmacother 9(5):767-786. https://doi.org/10.1517/14656 566.9.5.767

4. Legosz P, Otworowski M, Sibilska A, Starszak K, Kotrych D, Kwapisz A, Synder M (2019) Heterotopic ossification: a challenging complication of total hip arthroplasty: risk factors, diagnosis, prophylaxis, and treatment. Biomed Res Int 2019:3860142. https ://doi.org/10.1155/2019/3860142 
5. Lee A, Amin NP (2020) Radiation therapy for heterotopic ossification prophylaxis. In: StatPearls. Treasure Island (FL),

6. Neal BC, Rodgers A, Clark T, Gray H, Reid IR, Dunn L, MacMahon SW (2000) A systematic survey of 13 randomized trials of non-steroidal anti-inflammatory drugs for the prevention of heterotopic bone formation after major hip surgery. Acta Orthop Scand 71(2):122-128. https://doi.org/10.1080/000164700317413 076

7. Buvanendran A, Kroin JS, Berger RA (2007) Preoperative cyclooxygenase-2 inhibitor treatment reduces the incidence of heterotopic ossification after hip arthroplasty: six-month followup. Anesthesiology 107(2):358-359. https://doi.org/10.1097/01. anes.0000271873.86164.74

8. Brunnekreef JJ, Hoogervorst P, Ploegmakers MJ, Rijnen WH, Schreurs BW (2013) Is etoricoxib effective in preventing heterotopic ossification after primary total hip arthroplasty? Int Orthop 37(4):583-587. https://doi.org/10.1007/s00264-013-1781-0

9. Board TN, Karva A, Board RE, Gambhir AK, Porter ML (2007) The prophylaxis and treatment of heterotopic ossification following lower limb arthroplasty. J Bone Joint Surg Br 89(4):434-440. https://doi.org/10.1302/0301-620X.89B4.18845

10. Bek D, Beksac B, Della Valle AG, Sculco TP, Salvati EA (2009) Aspirin decreases the prevalence and severity of heterotopic ossification after 1-stage bilateral total hip arthroplasty for osteoarthrosis. J Arthroplasty 24(2):226-232. https://doi.org/10.1016/j. arth.2007.11.008

11. Alijanipour P, Patel RP, Naik TU, Parvizi J (2017) Heterotopic ossification in primary total hip arthroplasty using the direct anterior vs direct lateral approach. J Arthroplasty 32(4):1323-1327. https://doi.org/10.1016/j.arth.2016.11.030

12. Li T, Puhan MA, Vedula SS, Singh S, Dickersin K, Working A-A, G, (2011) Network meta-analysis-highly attractive but more methodological research is needed. BMC Med 9:79. https://doi. org/10.1186/1741-7015-9-79

13. Hutton B, Salanti G, Caldwell DM, Chaimani A, Schmid CH, Cameron C, Ioannidis JP, Straus S, Thorlund K, Jansen JP, Mulrow C, Catala-Lopez F, Gotzsche PC, Dickersin K, Boutron I, Altman DG, Moher D (2015) The PRISMA extension statement for reporting of systematic reviews incorporating network meta-analyses of health care interventions: checklist and explanations. Ann Intern Med 162(11):777-784. https://doi.org/10.7326/M14-2385

14. Howick J CI, Glasziou P, Greenhalgh T, Heneghan C, Liberati A, Moschetti I, Phillips B, Thornton H, Goddard O, Hodgkinson M (2011) The 2011 Oxford Levels of Evidence. Oxford Centre for Evidence-Based Medicine Available at https://www.cebmnet/ indexaspx $? \mathrm{o}=5653$

15. van der Heide HJ, Koorevaar RC, Lemmens JA, van Kampen A, Schreurs BW (2007) Rofecoxib inhibits heterotopic ossification after total hip arthroplasty. Arch Orthop Trauma Surg 127(7):557561. https://doi.org/10.1007/s00402-006-0243-1

16 Brooker AF, Bowerman JW, Robinson RA, Riley LH Jr (1973) Ectopic ossification following total hip replacement: Incidence and a method of classification. J Bone Joint Surg Am 55(8):1629-1632

17. Bland JM, Altman DG (2000) Statistics notes. The odds ratio. BMJ 320(7247):1468. https://doi.org/10.1136/bmj.320.7247.1468

18. Migliorini F, Aretini P, Driessen A, El Mansy Y, Quack V, Tingart M, Eschweiler J (2020) Better outcomes after mini-subvastus approach for primary total knee arthroplasty: a Bayesian network meta-analysis. Eur J Orthop Surg Traumatol. https://doi. org/10.1007/s00590-020-02648-9

19. Migliorini F, Eschweiler J, Trivellas A, Rath B, Driessen A, Tingart M, Arentini P (2020) Implant positioning among the surgical approaches for total hip arthroplasty: a Bayesian network metaanalysis. Arch Orthop Trauma Surg 140(8):1115-1124. https:// doi.org/10.1007/s00402-020-03448-w
20. Migliorini F, Trivellas A, Eschweiler J, Driessen A, Lessi F, Tingart M, Aretini P (2020) Nerve palsy, dislocation and revision rate among the approaches for total hip arthroplasty: a Bayesian network meta-analysis. Musculoskelet Surg. https://doi.org/10.1007/ s12306-020-00662-y

21. Migliorini F, Trivellas A, Eschweiler J, El Mansy Y, Mazzanti MC, Tingart M, Arentini P (2020) Hospitalization length, surgical duration, and blood lost among the approaches for total hip arthroplasty: a Bayesian network meta-analysis. Musculoskelet Surg. https://doi.org/10.1007/s12306-020-00657-9

22 Ahrengart L, Blomgren G, Tornkvist H (1994) Short-term ibuprofen to prevent ossification after hip arthroplasty: no effects in a prospective randomized study of 47 arthrosis cases. Acta OrthopScand 65(2):139-141. https://doi.org/10.3109/1745367940 8995421

23. Barthel T, Baumann B, Noth U, Eulert J (2002) Prophylaxis of heterotopic ossification after total hip arthroplasty: a prospective randomized study comparing indomethacin and meloxicam. Acta Orthop Scand 73(6):611-614. https://doi.org/10.1080/00016 4702321039543

24. Burssens A, Thiery J, Kohl P, Molderez A, Haazen L (1995) Prevention of heterotopic ossification with tenoxicam following total hip arthroplasty: a double-blind, placebo-controlled dose-finding study. Acta Orthop Belg 61(3):205-211

25 Dorn U, Grethen C, Effenberger H, Berka H, Ramsauer T, Drekonja T (1998) Indomethacin for prevention of heterotopic ossification after hip arthroplasty: a randomized comparison between 4 and 8 days of treatment. Acta OrthopScand 69(2):107-110. https ://doi.org/10.3109/17453679809117607

26. Elmstedt E, Lindholm TS, Nilsson OS, Tornkvist H (1985) Effect of ibuprofen on heterotopic ossification after hip replacement. Acta Orthop Scand 56(1):25-27. https://doi.org/10.3109/17453 678508992973

27. Fransen M, Anderson C, Douglas J, MacMahon S, Neal B, Norton R, Woodward M, Cameron ID, Crawford R, Lo SK, Tregonning G, Windolf M, Group HC (2006) Safety and efficacy of routine postoperative ibuprofen for pain and disability related to ectopic bone formation after hip replacement surgery (HIPAID): randomised controlled trial. BMJ 333(7567):519. https://doi. org/10.1136/bmj.38925.471146.4F

28 Gebuhr P, Soelberg M, Orsnes T, Wilbek H (1991) Naproxen prevention of heterotopic ossification after hip arthroplasty: a prospective control study of 55 patients. Acta OrthopScand 62(3):226-229. https://doi.org/10.3109/17453679108993597

29. Gebuhr P, Sletgard J, Dalsgard J, Soelberg M, Keisu K, Hanninen A, Crawford M (1996) Heterotopic ossification after hip arthroplasty: a randomized double-blind multicenter study tenoxicam in 147 hips. Acta Orthop Scand 67(1):29-32. https://doi. org/10.3109/17453679608995604

30. Grohs JG, Schmidt M, Wanivenhaus A (2007) Selective COX-2 inhibitor versus indomethacin for the prevention of heterotopic ossification after hip replacement: a double-blind randomized trial of 100 patients with 1-year follow-up. Acta Orthop 78(1):95-98. https://doi.org/10.1080/17453670610013484

31. Kienapfel H, Koller M, Wust A, Sprey C, Merte H, EngenhartCabillic R, Griss P (1999) Prevention of heterotopic bone formation after total hip arthroplasty: a prospective randomised study comparing postoperative radiation therapy with indomethacin medication. Arch Orthop Trauma Surg 119(5-6):296-302. https ://doi.org/10.1007/s004020050414

32 Kjaersgaard-Andersen P, Nafei A, Teichert G, Kristensen O, Schmidt SA, Keller J, Lucht U (1993) Indomethacin for prevention of heterotopic ossification: a randomized controlled study in 41 hip arthroplasties. Acta OrthopScand 64(6):639-642. https:// doi.org/10.3109/17453679308994587 
33 Knelles D, Barthel T, Karrer A, Kraus U, Eulert J, Kolbl O (1997) Prevention of heterotopic ossification after total hip replacement: a prospective, randomised study using acetylsalicylic acid, indomethacin and fractional or single-dose irradiation. J Bone Joint Surg Br 79(4):596-602. https://doi. org/10.1302/0301-620x.79b4.6829

34. Kolbl O, Knelles D, Barthel T, Kraus U, Flentje M, Eulert J (1997) Randomized trial comparing early postoperative irradiation vs. the use of nonsteroidal antiinflammatory drugs for prevention of heterotopic ossification following prosthetic total hip replacement. Int J Radiat Oncol Biol Phys 39(5):961-966. https://doi.org/10.1016/ s0360-3016(97)00496-3

35. Kolbl O, Knelles D, Barthel T, Raunecker F, Flentje M, Eulert J (1998) Preoperative irradiation versus the use of nonsteroidal antiinflammatory drugs for prevention of heterotopic ossification following total hip replacement: the results of a randomized trial. Int J Radiat Oncol Biol Phys 42(2):397-401. https://doi.org/10.1016/ s0360-3016(98)00204-1

36. Legenstein R, Bosch P, Ungersbock A (2003) Indomethacin versus meloxicam for prevention of heterotopic ossification after total hip arthroplasty. Arch Orthop Trauma Surg 123(2-3):91-94. https:// doi.org/10.1007/s00402-003-0487-y

37. Neal BC, Rodgers A, Gray H, Clark T, Beaumont DD, House T, Douglas JE, Reid IR, MacMahon SW (2000) No effect of lowdose aspirin for the prevention of heterotopic bone formation after total hip replacement: a randomized trial of 2,649 patients. Acta Orthop Scand 71(2):129-134. https://doi.org/10.1080/00016 4700317413085

38 Persson PE, Sodemann B, Nilsson OS (1998) Preventive effects of ibuprofen on periarticular heterotopic ossification after total hip arthroplasty: a randomized double-blind prospective study of treatment time. Acta OrthopScand 69(2):111-115. https://doi. org $/ 10.3109 / 17453679809117608$

39. Reis HJ, Kusswetter W, Schellinger T (1992) The suppression of heterotopic ossification after total hip arthroplasty. Int Orthop 16(2):140-145. https://doi.org/10.1007/BF00180205

40. Saudan M, Saudan P, Perneger T, Riand N, Keller A, Hoffmeyer $P$ (2007) Celecoxib versus ibuprofen in the prevention of heterotopic ossification following total hip replacement: a prospective randomised trial. J Bone Joint Surg Br 89(2):155-159. https://doi. org/10.1302/0301-620X.89B2.17747

41. Schmidt SA, Kjaersgaard-Andersen P, Pedersen NW, Kristensen SS, Pedersen P, Nielsen JB (1988) The use of indomethacin to prevent the formation of heterotopic bone after total hip replacement: a randomized, double-blind clinical trial. J Bone Joint Surg Am 70(6):834-838

42. van der Heide HJ, Spruit M, Slappendel R, Klooster N, van Limbeek J (2004) Prophylaxis for heterotopic ossification after primary total hip arthroplasty: a cohort study between indomethacin and meloxicam. Acta Orthop Belg 70(3):240-246

43. van der Heide HJ, Rijnberg WJ, Van Sorge A, Van Kampen A, Schreurs BW (2007) Similar effects of rofecoxib and indomethacin on the incidence of heterotopic ossification after hip arthroplasty. Acta Orthop 78(1):90-94. https://doi.org/10.1080/17453 670610013475

44. Vielpeau C, Joubert JM, Hulet C (1999) Naproxen in the prevention of heterotopic ossification after total hip replacement. Clin Orthop Relat Res 369:279-288. https://doi.org/10.1097/00003 086-199912000-00029

45 Wahlstrom O, Risto O, Djerf K, Hammerby S (1991) Heterotopic bone formation prevented by diclofenac: prospective study of 100 hip arthroplasties. Acta OrthopScand 62(5):419-421. https://doi. org/10.3109/17453679108996636
46. Winkler S, Springorum HR, Vaitl T, Handel M, Barta S, Kehl V, Craiovan B, Grifka J (2016) Comparative clinical study of the prophylaxis of heterotopic ossifications after total hip arthroplasty using etoricoxib or diclofenac. Int Orthop 40(4):673-680. https:// doi.org/10.1007/s00264-015-3077-z

47. Zhao WG, Liu L, Li XL, ZW Liu, (2011) Celecoxib prevents against heterotopic ossification after total hip arthroplasty. J Clin Rehabilitative Tissue Eng Res 15:9760-9763

48. Cai L, Wang Z, Luo X, She W, Zhang H (2019) Optimal strategies for the prevention of heterotopic ossification after total hip arthroplasty: a network meta-analysis. Int J Surg 62:74-85. https ://doi.org/10.1016/j.ijsu.2018.12.011

49. Iorio R, Healy WL (2002) Heterotopic ossification after hip and knee arthroplasty: risk factors, prevention, and treatment. J Am Acad Orthop Surg 10(6):409-416. https://doi.org/10.5435/00124 635-200211000-00005

50. Balboni TA, Gobezie R, Mamon HJ (2006) Heterotopic ossification: Pathophysiology, clinical features, and the role of radiotherapy for prophylaxis. Int J Radiat Oncol Biol Phys 65(5):12891299. https://doi.org/10.1016/j.ijrobp.2006.03.053

51. Mourad WF, Packianathan S, Shourbaji RA, Russell G, Khan MA, Vijayakumar S (2012) Radiation-induced sarcoma following radiation prophylaxis of heterotopic ossification. Pract Radiat Oncol 2(2):151-154. https://doi.org/10.1016/j.prro.2011.06.005

52. Farris MK, Chowdhry VK, Lemke S, Kilpatrick M, Lacombe M (2012) Osteosarcoma following single fraction radiation prophylaxis for heterotopic ossification. Radiat Oncol 7:140. https://doi. org/10.1186/1748-717X-7-140

53. Lavernia CJ, Contreras JS, Villa JM, Rossi MD (2014) Celecoxib and heterotopic bone formation after total hip arthroplasty. J Arthroplasty 29(2):390-392. https://doi.org/10.1016/j. arth.2013.06.039

54. Oni JK, Pinero JR, Saltzman BM, Jaffe FF (2014) Effect of a selective COX-2 inhibitor, celecoxib, on heterotopic ossification after total hip arthroplasty: a case-controlled study. Hip Int 24(3):256-262. https://doi.org/10.5301/hipint.5000109

55. Sell S, Willms R, Jany R, Esenwein S, Gaissmaier C, Martini F, Bruhn G, Burkhardsmaier F, Bamberg M, Kusswetter W (1998) The suppression of heterotopic ossifications: radiation versus NSAID therapy-a prospective study. J Arthroplasty 13(8):854859. https://doi.org/10.1016/s0883-5403(98)90189-9

56. Zhu XT, Chen L, Lin JH (2018) Selective COX-2 inhibitor versus non-selective COX-2 inhibitor for the prevention of heterotopic ossification after total hip arthroplasty: A meta-analysis. Medicine (Baltimore) 97(31):e11649. https://doi.org/10.1097/MD.00000 00000011649

57 Joice M, Vasileiadis GI, Amanatullah DF (2018) Non-steroidal anti-inflammatory drugs for heterotopic ossification prophylaxis after total hip arthroplasty: a systematic review and meta-analysis. Bone Joint J 100(7):915-922

58. Weber EW, Slappendel R, Durieux ME, Dirksen R, van der Heide H, Spruit M (2003) COX 2 selectivity of non-steroidal antiinflammatory drugs and perioperative blood loss in hip surgery: a randomized comparison of indomethacin and meloxicam. Eur J Anaesthesiol 20(12):963-966. https://doi.org/10.1017/s0265 021503001558

Publisher's Note Springer Nature remains neutral with regard to jurisdictional claims in published maps and institutional affiliations. 